\title{
TECNOLOGIA CUIDATIVO-EDUCACIONAL PARA APOIO AOS HOMENS NO ENFRENTAMENTO À PANDEMIA DO CORONAVÍRUS
}

\author{
Clea Conceição Leal Borges ${ }^{1}$ \\ Anderson Reis de Sousa ${ }^{2}$ \\ https://orcid.org/0000-0002-9523-6272 \\ https://orcid.org/0000-0001-8534-1960 \\ Isabella Félix Meira ${ }^{1}$ \\ Cléton Salbego \\ https://orcid.org/0000-0002-0631-994X \\ https://orcid.org/0000-0001-7774-6327 \\ https://orcid.org/0000-0002-6200-1995 \\ Anatanailson Reis Santos ${ }^{1}$ \\ $\begin{array}{ll}\text { Bernardo Haylan de Souza do Carmo Lobo }{ }^{1} & \text { https://orcid.org/0000-0001-8606-5830 } \\ \text { Rafael Pereira dos Reis } & \text { https://orcid.org/0000-0001-5206-8849 }\end{array}$ \\ Álvaro Pereira $^{1} \quad$ https://orcid.org/0000-0003-1899-7374
}

Objetivo: Descrever a construção de uma tecnologia cuidativo-educacional voltada ao apoio de homens para o enfrentamento da pandemia do Coronavírus no Brasil. Método: Estudo metodológico, realizada de março a abril de 2020 com 1.015 homens, no Brasil. A produção tecnológica foi estruturada em quatro etapas, subsidiada pelo modelo teórico-conceitual de Tecnologia Cuidativo-Educacional. Resultados: O trabalho resultou na construção de um guia digital para orientações de apoio ao enfrentamento de homens à pandemia no novo Coronavírus no Brasil. Considerações Finais: O recurso tecnológico torna-se uma ferramenta facilitadora do enfrentamento de homens à pandemia do novo Coronavírus no Brasil.

Descritores: Pandemias; Infecções por Coronavirus; Saúde do homem; Assistência à Saúde; Enfermagem; Tecnologia Educacional.

\section{CARE-EDUCATIONAL TECHNOLOGY TO SUPPORT MEN IN FACING THE CORONAVIRUS PANDEMIC}

Objective: To describe the construction of a caring-educational technology aimed at supporting men to face the Coronavirus pandemic in Brazil. Method: Methodological study, carried out from March to April 2020 with 1,015 men, in Brazil. The technological production was structured in four stages, subsidized by the theoretical-conceptual model of Care-Educational Technology. Results: The work resulted in the construction of a digital guide for guidelines to support the confrontation of men to the pandemic in the new Coronavirus in Brazil. Final Considerations: The technological resource becomes a tool that facilitates the confrontation of men to the pandemic of the new Coronavirus in Brazil.

Descriptors: Pandemics; Coronavirus infections; Men's Health; Health Assistance; Nursing; Educational technology.

\section{TECNOLOGÍA EDUCATIVA DE CUIDADO PARAAPOYAR A LOS HOMBRES ENFRENTAR LA PANDEMIA DE CORONAVIRUS}

Objetivo: Describir la construcción de una tecnología educativa y solidaria destinada a ayudar a los hombres a enfrentar la pandemia de coronavirus en Brasil. Método: Estudio metodológico, realizado de marzo a abril de 2020 con 1.015 hombres, en Brasil. La producción tecnológica se estructuró en cuatro etapas, subsidiada por el modelo teórico-conceptual de Tecnología Educativa-Cuidado. Resultados: El trabajo resultó en la construcción de una guía digital de pautas para apoyar la confrontación de los hombres a la pandemia en el nuevo Coronavirus en Brasil. Consideraciones finales: El recurso tecnológico se convierte en una herramienta que facilita la confrontación de los hombres con la pandemia del nuevo coronavirus en Brasil.

Descriptores: Pandemias; Infecciones por coronavirus; Salud de los hombres; Asistencia de salud; Enfermería; Tecnologia Educacional.

'Escola de Enfermagem da Universidade Federal da Bahia, BA.

${ }^{2}$ Escola de Enfermagem da Universidade do Estado da Bahia, BA.

Universidade Federal de Santa Maria, RS.

Autor correspondente: Clea Conceição Leal Borges Email: anderson.sousa@ufba.br

Recebido:01/5/2020 Aceito: 09/6/2020 


\section{INTRODUÇÃO}

O marco atual e desafiador para a saúde mundial, concentra-se no surgimento do novo Coronavírus, denominado (SARS-CoV-2), agente causador da COVID-19 (Coronavirus disease 2019), descoberto em dezembro de 2019 na cidade de Wuhan, na China(1). O novo coronavírus é derivado da família de vírus tipo Coronaviridae, responsável por uma variedade de infecções respiratórias nos seres humanos, além da COVID-19, sendo geradora de ações expressivas de enfrentamento, que vão desde a adoção de medidas farmacológicas, até as ações simples, como o foco do controle do ambiente ${ }^{2}$.

Com o advento da transmissão viral, a COVID-19, que possui uma ágil disseminação, alcançou rapidamente várias partes do planeta, sendo reconhecida por entidades sanitárias globais - como a Organização Mundial da Saúde (OMS), como uma pandemia ${ }^{3}$. Geradora de significativas repercussões e impactos, a pandemia resultou em uma transformação no modo de vida social, onde se fez necessário adotar medidas para conter a propagação da doença, assim como para conhecer a mesma e desenvolver estratégias de enfrentamento ${ }^{4}$. Uma dessas medidas incluiu determinações sanitárias que foram acolhidas por grande parte ou quase a totalidade dos países afetados, a exemplo da quarentena e o isolamento social, as quais afetaram a vida das pessoas, que abruptamente, tiveram mudanças em seu cotidiano ${ }^{5}$.

Na busca por compreender como os homens conceberam e se comportaram diante da pandemia no Brasil, uma vez que esse grupo compõe um recorte populacional significativo nos casos de incidência, além de ser responsável pela maior força de trabalho e em especial nos serviços essenciais, e que por outro lado representam um público "chave" decorrente da histórica tradição masculina em resistir e até mesmo negligenciar à adesão à medidas terapêuticas em saúde, ampliou-se as investigações sobre o assunto ${ }^{6-7}$.

O que tem sido observado no Brasil com a determinação das medidas de isolamento social, é que homens em grande parte já habituados a uma jornada de trabalho intensa e massiva, tiveram que alterar o desempenho das suas práticas cotidianas, incluindo as laborais, resguardando-se em seus lares, e alguns deles em outros espaços, dado que há um número elevado de homens brasileiros em situação de rua, sem abrigo e em privação de liberdade no sistema penitenciário.

Com a chegada da pandemia no país em função da massiva campanha midiática, ações de políticas públicas, de coletivos, movimentos sociais e de bairro, novas práticas de cuidado à saúde tiveram que ser acatadas pela população masculina, com o objetivo de impedir a transmissão em larga escala do vírus. Entre essas práticas destacam-se o uso de máscaras faciais de proteção individual, de álcool em gel para higiene das mãos e a higienização frequente das mãos e do ambiente ${ }^{8}$. Associadas a realização dessas medidas, novos contextos tornaram-se mais problemáticos, descortinando vulnerabilidades, desigualdades, iniquidades e outros dilemas estruturais como o racismo e a discriminação, o estigma, conflitos políticos e ideológicos, ampliação do fundamentalismo religioso, surgimento de teorias conspiratórias, em especial àqueles homens de classe social mais baixa, pretos, residentes em favelas, subúrbios e territórios distantes das grandes cidades e da oferta de recursos e tecnologias, como ocorridos em pandemias passadas 9 .

Especificamente no Brasil, marcadores de gênero e masculinidades permeiam o contexto pandêmico no país, ao se observar que o primeiro caso confirmado de Coronavírus (SARS-CoV2) foi de um homem, assim como as primeiras mortes, os maiores índices de internamento e mortalidade. Tal panorama, suscita um olhar mais ampliado e o aprofundamento teórico científico de investigação sobre essas razões ${ }^{8}$.

Como forma de apoiar a vivência de um novo momento como é o surgimento de uma pandemia, torna-se essencial levantar soluções programáticas que sejam capazes de desenvolver estratégias de enfrentamento, em especial que auxiliem as pessoas para lidar de forma saudável, segura e consciente, minimizando medos, ansiedade, reduzindo e/ou eliminando mitos, fake news (fenômeno recente nessa geração pandêmica) e que potencialize a aceitação, o autocontrole e a regulação emocional dos homens, a partir da educação e comunicação cuidativa em saúde. Nesse sentido, as tecnologias cuidativo-educacionais (TCE) ${ }^{10}$ se apresentam como uma possibilidade inovadora de conceber/justificar produtos e processos tecnológicos desenvolvidos, validados e/ou utilizados, sob uma perspectiva que transcenda meramente sua concepção como tecnologias educacionais ou assistenciais de modo isolado, ou seja, sem que haja a inter-relação entre o cuidar-educar. No contexto de atenção à saúde em tempos da COVID-19, torna-se necessário a construção de ferramentas que subsidiem o processo de cuidar-educar deste público. As TCE devem emergir da práxis dos sujeitos a que se destinam, para que seu significado seja a resolução das necessidades de saúde individual e/ou coletiva ${ }^{10}$

Neste sentido o estudo foi guiado pela questão de investigação: como construir uma tecnologia cuidativo-educacional para o apoio de homens durante o enfrentamento da pandemia do novo Coronavírus (SARS-CoV2) no Brasil? Como forma de responder a essa indagação, este estudo teve como objetivo descrever a construção de uma tecnologia cuidativo-educacional voltada ao apoio de homens para o enfrentamento da pandemia do novo Coronavírus (SARS-CoV2) no Brasil. 


\section{MÉTODO}

\section{Tipo do estudo}

Trata-se de um estudo metodológico, descritivo subsidiado pelo modelo teórico-conceitual de Tecnologia Cuidativo-Educacional (TCE) ${ }^{10}$, dedicada ao fornecimento de orientações para apoio de homens no enfrentamento à pandemia pelo novo Coronavirus (SARS-CoV2) no Brasil. Esta construção seguiu quatro etapas: diagnóstico da realidade, teorização/desenvolvimento, apreciação, desenho final.

\section{Etapa 1 - Diagnóstico da realidade}

Por meio da pesquisa matricial intitulada "Atitudes e estratégias de enfrentamento de homens à pandemia do novo Coronavirus (SARS-CoV2) no Brasil", foi possivel identificar caracteristicas sociodemográficas, laborais, atitudinais, emocionais e as estratégias de enfrentamento adotadas pelos homens frente ao Coronavirus (SARS-CoV2).

Figura 1 - Logomarca da pesquisa nacional Atitudes e estratégias de enfrentamento de homens à pandemia do novo Coronavírus no Brasil. Salvador, Bahia, Brasil, 2020.

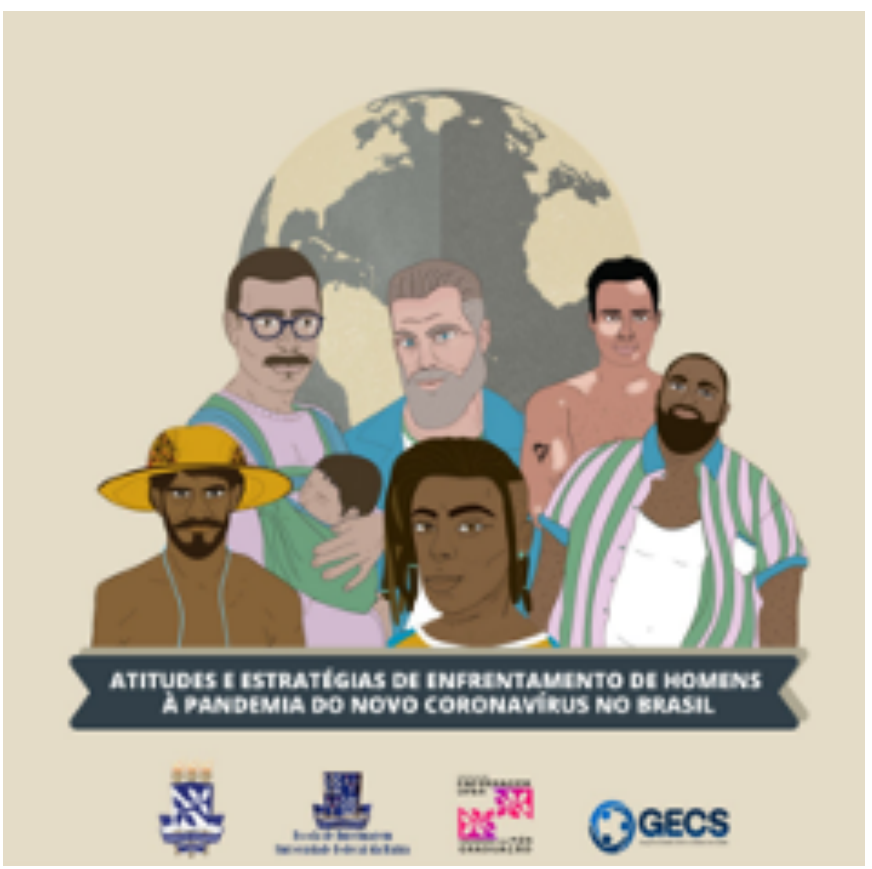

Fonte: Dados da pesquisa, Salvador, Bahia, Brasil, 2020.

A coleta dos dados ocorreu entre março e abril de 2020 por meio de formulário disponibilizado em plataforma on-line. Foi disponibilizado link de acesso via redes sociais (Facebook, Instagram, WhatsApp), aplicando a técnica de coleta bola de neve, obtendo alcance em todo território nacional. Participaram da pesquisa 1.015 homens adultos residentes no Brasil.
Um resultado emergente desta investigação, foi a construção de uma ferramenta que instrumentaliza-se o público homem para o enfrentamento da pandemia de Coronavírus. Após análise dos formulários, foi identificada a necessidade da construção de uma guia para ser disponibilizado por meio digital.

\section{Etapa 2 - Teorização/desenvolvimento}

Fez-se o levantamento na literatura, com acesso à editoriais, livros, artigos, boletins epidemiológicos, em consonância com os eixos temáticos e as diretrizes da Política Nacional de Atenção Integral à Saúde do Homem (PNAISH) do Ministério da Saúde, além de notícias em meios impressos e digitais em busca de subsídios teóricos sobre a temática do novo Coronavírus. Este movimento buscou elencar indicadores epidemiológicos, sinais e sintomas, medidas de prevenção e tratamento e demais práticas de cuidado à saúde de maior aderência por parte do público masculino e elementos próprios do contexto da pandemia.

A construção teórico-metodológica da TCE foi planejada a partir de reuniões entre grupo de pesquisadores composto por docentes e estudantes dos cursos de Graduação Mestrado e Doutorado em Enfermagem e Saúde, da Escola de Enfermagem da Universidade Federal da Bahia (UFBA) e pesquisadores das áreas de Linguística, Pedagogia, Psicologia e Serviço Social. Foram realizadas cinco reuniões via WhatsApp para avaliar a produção sobre o tema e destacar as principais informações que estivessem relacionadas com o modo como o público masculino enfrentaria o contexto pandêmico no país, como estratégia de reconhecimento dos elementos constituintes do guia.

A revisão de literatura subsidiou o desenvolvimento dos elementos textuais e imagéticos que compuseram a tecnologia. Cada elemento foi analisado entre o grupo de pesquisa e as pactuações finais foram repassadas à profissional diagramador que colaborou no desenvolvimento deste guia.

\section{Etapa 3 e 4 - Apreciação e Desenho final}

Após a produção da primeira versão do guia, foram realizadas quatro reuniões para apreciação do conteúdo semântico e imagético da TCE pelos pesquisadores.

As ilustrações de textos foram apreciadas juntamente com profissional da área de designer e linguística, como forma de aprimorar a criação. Foram apreciados conceitos, estética, plástica e a configuração de um layout próprio. Desse modo, atentou-se para a coerência entre o quantitativo das ilustrações utilizadas e a expressividade das mesmas. 
Figura 2 - Estrutura de elaboração da tecnologia cuidativo-educacional de orientações de apoio ao enfrentamento de homens à pandemia do novo Coronavírus (SARS-CoV2) no Brasil. Salvador, 2020.

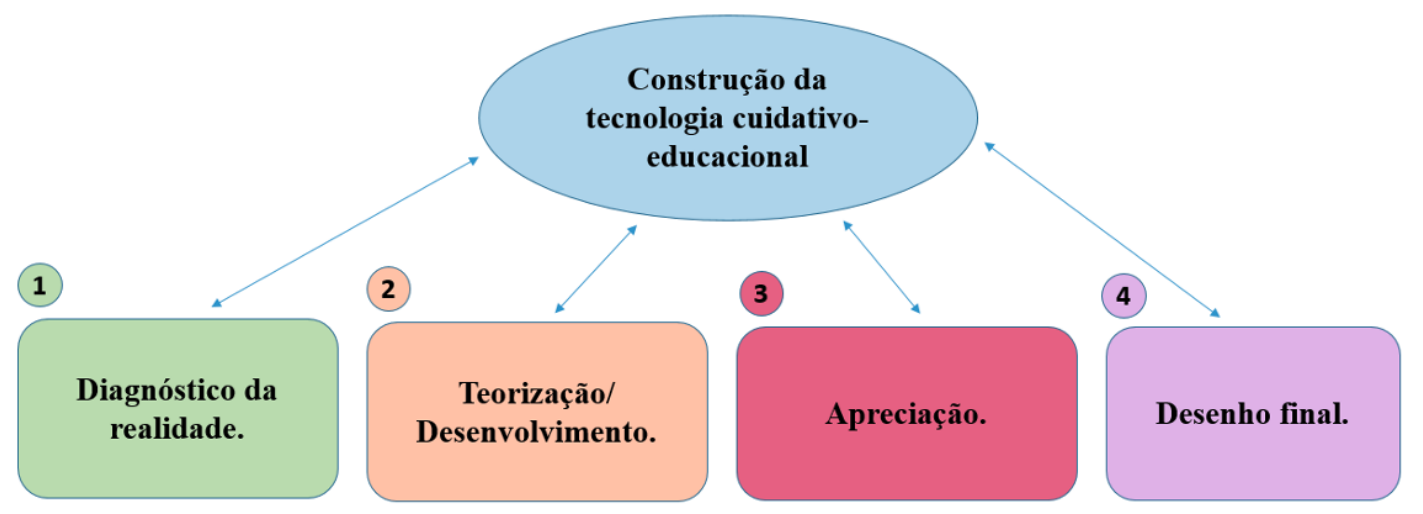

\section{* Todas as atividades ocorreram remotamente por meio do suporte de recursos digitais.}

\section{Aspectos éticos}

O estudo foi realizado seguindo as recomendações éticas emitidas pela Resolução do Conselho Nacional de Saúde no 466/12, que aborda a pesquisa em seres humanos, respaldado nos aspectos éticos e legais. A pesquisa foi aprovada pelo Comitê de Ética em Pesquisa da Universidade Federal da Bahia (UFBA), sob o parecer de número: 3.313.517.

Cumpriu-se em todas as etapas de operacionalização do estudo os critérios éticos. Para tanto, o estudo foi aprovado pelo Comitê de Ética em Pesquisa (CEP), e regulamentação da Comissão Nacional de Ética em Pesquisa (CONEP), sob o parecer de número: 3.960.330. A fim de preservar o rigor da pesquisa científica, atendeu-se aos critérios do Revised Standards for Quality Improvement Reporting Excellence, SQUIRE 2.0.

\section{OBJETIVOS DA INOVAÇÃO}

Contribuir com a promoção do (auto)cuidado e o fortalecimento da educação em saúde direcionada ao apoio do público masculino no enfrentamento da pandemia do novo Coronavírus
(SARS-CoV2) no Brasil.

\section{DESCRIÇÃO DAINOVAÇÃO}

A construção da tecnologia cuidativo-educacional se deu a partir da execução de quatro etapas, permitindo constituir um guia de orientações para apoio à homens no enfrentamento à pandemia do novo Coronavírus no Brasil.

\section{PRINCIPAIS RESULTADOS ALCANÇADOS}

Os homens eram em sua maioria cisgêneros (93,6\%), gays (47,7\%), com faixa etária entre 18 e 67 anos, de raça/cor autoreferida parda (39,3\%), com ensino superior completo $(66,7 \%)$, residentes na região Nordeste do país (72,3\%), convivendo com familiares não idosos (21,95\%), residindo em casas (67,45\%), com renda aproximada acima de cinco salários mínimos (33,2\%).

As informações/conteúdos mais expressas pelos homens na pesquisa de diagnóstico demonstrou diversas atitudes e estratégias de enfrentamento dos homens diante do contexto da pandemia do novo Coronavírus (SARS-CoV2) no Brasil. Estas estão descritas por núcleos temáticos, no quadro a seguir.

Quadro 1 - Informações/conteúdos apreendidos no diagnóstico da realidade para elaboração da tecnologia cuidativo-educacional. Salvador, Bahia, 2020.

\begin{tabular}{|l|l|}
\hline \multicolumn{1}{|c|}{ Tema } & \multicolumn{1}{c|}{ Conteúdos } \\
\hline Preocupações & $\begin{array}{l}\text { Condição de saúde individual e familiar; fragilidades nas relações conjugais, afetivas e se- } \\
\text { xuais; dados à interação social; dados à situação acadêmica e profissional incertas; situa- } \\
\text { ção econômica e de trabalho. }\end{array}$ \\
\hline Atitudes & Busca discreta e limitada de apoio; mudança de hábitos; manter-se informado. \\
\hline Emoções & Ansiedade; apreensão; insegurança; impotência; medo. \\
\hline Estratégias de enfrentamento & $\begin{array}{l}\text { Atividades de distração (acessar conteúdo na internet, interagir nas redes sociais); menta- } \\
\text { lização positiva; minimização de conflitos conjugais e familiares. }\end{array}$ \\
\hline
\end{tabular}


As informações/conteúdos levantados na literatura científica buscaram atender as demandas levantadas pelos homens na pesquisa de conhecimento. Adequou-se os conteúdos às necessidades específicas e cotidianas da população masculina, como forma de promover uma corrente de adaptação transcultural, considerando a diversidade de expressões das masculinidades dos homens brasileiros.

Em consonância com a avaliação da coerência e essencialidade dos conteúdos apreendidos na literatura, analisou-se o grau de importância e persistência no que tange ao alcance do objetivo central: apoiar a população masculina no enfrentamento do contexto pandêmico. Para tanto avaliou-se a qualidade das produções científicas, a ligação com os fenômenos geradores pela pandemia no comportamento e na organização social da população masculina no Brasil frente a esse cenário. Além do grau de importância, verificou-se a capacidade dos conteúdos de serem convidativos e instigantes, passiveis de serem geradores de mudanças de comportamento e atitudes, assim como fosse capaz de aportar apoio às medidas e/ou estratégias e/ou práticas de enfrentamento à pandemia, por parte de homens adultos.

A fim de garantir o cumprimento do alcance do rigor científico atingido pelos conteúdos abordados no produto tecnológico, construiram-se os mesmos com bases sustentadas na literatura, com potencial elevado para circulação do produto no meio científico da área, assim como em consonância com os objetivos do Ministério da Saúde no que tange ao cuidado à saúde da população masculina, a exemplo da Política Nacional de Atenção Integral à Saúde do Homem (PNAISH) ${ }^{11}$, que foi tomada como pilar de consulta, a partir dos seus eixos de atenção, bem como das suas diretrizes e objetivos.

A estrutura da tecnologia cuidativo-educacional (guia de orientações de apoio) foi precedida pela organização de sessões temáticas, formatação, recursos gráficos e gramaticais, editoração e publicação, descritos a seguir.

Neste sentido, o guia foi dividido em sessões, compondo os seguintes tópicos principais:

1. Apresentação;

2. O que é o novo Coronavírus?;

3. Comportamento social da pessoa adulta e a transmissão pelo novo;

4. Coronavírus;

5. O que é a COVID-19?;

6. Como a manifestação da doença (COVID-19) ocorre?;

7. Quais são os sinais e sintomas mais presentes na Covid-19?

8. Como enfrentar a pandemia?

9. Como lidar com a quarentena e o distanciamento social?
10. Como lidar com uma situação de crise?;

11. Como cuidar do bem-estar e bem viver durante a pandemia?:

12. Como cuidar da sua saúde física durante a pandemia?;

13. Saúde sexual reprodutiva e sexualidades;

14. Como cuidar da sua saúde ancestral e popular durante pandemia?

15. Como cuidar da sua saúde étnica/racial e cultural durante pandemia?;

16. Como cuidar da sua saúde mental durante a pandemia?;

17. Como cuidar da sua saúde bioenergética, espiritual, e religiosa durante a pandemia?;

18. Como cuidar da sua saúde familiar e do ambiente em que vive durante a pandemia?;

19. Como cuidar da sua saúde ocupacional e do trabalho durante a pandemia?

20. Mensagem final.

Para a organização da estrutura do guia, atentou-se para a apropriação do nível sociocultural dos conteúdos, bem como do cumprimento de uma sequência lógica do conteúdo proposto apresentado. Atendeu-se às normas gramaticais, para alcance da qualidade no quesito concordância e ortografia, estilo da escrita e redação, adequação da linguagem, como forma de corresponder ao nível de conhecimento da população alvo a ser destinada à tecnologia. Além disso, o material do guia foi processado por meio digital, em Portable Document Format (PDF), que permite exibir, compartilhar, o documento criado, por meio de um padrão aberto, que podem contar links. Com fins de garantir a propriedade intelectual, procedeu-se o produto tecnológico produzido à apreciação por parte de uma editora nacional, que registrou e publicou o mesmo no ISBN Número Internacional Padrão do Livro da Fundação (do inglês, International Standard Book Number) atribuído pela Fundação Biblioteca Nacional e do DOI (do inglês, Digital Object Identifier). Mediante a esse registro, publicou-se o guia em redes sociais de grande difusão no Brasil (Facebook, Instagram, Whatsapp), e em uma página própria criada pelo grupo de pesquisa no Instagram, intitulada: “@ cuidadoasaudedehomens", para publicação em largo alcance em todo o território nacional, quer seja por meio do acesso à internet a partir de computadores, tablets e outros, assim como os smartphone.

O estilo buscou atender as necessidades das normatizações da escrita, compreendo o uso adequado do tamanho das letras, a escolha das fontes, a inserção das cores das letras e dos fundos. Para tanto, seguiu-se uma padronização.

Quanto ao formato, adotou-se o tamanho A4, com enqua- 
dramento central, espaços laterais e espaçamento entre as linhas. O número de páginas foi adequado de acordo com as temáticas levantadas a partir das orientações a serem aportadas para cada tema. Acresceu à produção do guia a generalização do aprendizado, como forma de incluir diferentes públicos, incluindo desde o que se encontra na zona urbana, assim como aqueles que estão na zona rural. Para tanto, utilizou-se de aspectos-chaves (temáticas essenciais para a discussão do tema) e da ludicidade para o alcance da construção do conhecimento.

A inserção de personagens foi adotada como forma de ilustrar perfis de homens diversos, com arquétipos característicos, carregados de expressividades, considerando os marcadores de biotipo, identidade de gênero, raça/cor, território/cultura, atividade ocupacional, idade/geração, nível de escolaridade e profissionalização e classe social. Esses personagens compuseram a cartilha, sendo aplicado como quebra de sessões, numa espécie de organização de capítulos, expressos na forma de contracapa. Tal construção segue em convergência com a perspectiva relacional de gênero provocada pela Política Nacional de Atenção Integral à Saúde do Homem (PNAISH) ${ }^{12,13}$.

Partindo desse necessidade em promover avanços na implementação das políticas de saúde, reconhece-se o potencial das tecnologias, que aportam entre outros ganhos, uma importante contribuição na atuação de profissionais de saúde na rede de atenção, a exemplo da categoria profissio- nal de Enfermagem, como observados em outros cenários. ${ }^{14}$ Além disso, cabe enfatizar o crescente avanço das tecnologias da informação e comunicação em todo o planeta, sendo transformadoras de processos humanos, tais como das ações de produção do cuidado, necessitando tem potencializadas e refinadas a fim de que estejam acessiveis à população ${ }^{14}$

Em convergência com essa necessidade de avanço e projeção das tecnologias cuidativas em saúde, enfatiza-se o quanto a instituição de incrementos a serem inseridos no sistema de saúde pode ser capaz de alcanças status satisfatórios no que tange ao fortalecimento da prática profissional, a exemplo da Atenção Primária à Saúde, porta de entrada e nível base do Sistema Único de Saúde (SUS) brasileiro e tão essencial para a garantia da promoção da saúde. Observa-se nesse sentido, a projeção efetiva de tecnologias como os protocolos para o fortalecimento da qualidade, segurança e da ampliação do acesso aos serviços de saúde, tal como da valorização e visibilidade da Enfermagem nesse contexto ${ }^{15}$.

Outras ilustrações foram inseridas no guia, a fim de auxiliar na fixação do conhecimento teórico descrito e ampliar a possibilidade de "passar as mensagens" propostas, tematizando através dessas ilustrações, o contexto atual da vivência durante uma pandemia (quarentena, distanciamento social, isolamento domiciliar, comunicação por meio das redes sociais e outras), fortalecendo a chama impulsionada pela mídia de: "\#fica em casa".

Figura 3 - Páginas com conteúdo do guia de orientações e apoio para homens no enfrentamento à pandemia do novo Coronavírus (SARS-CoV2) no Brasil.
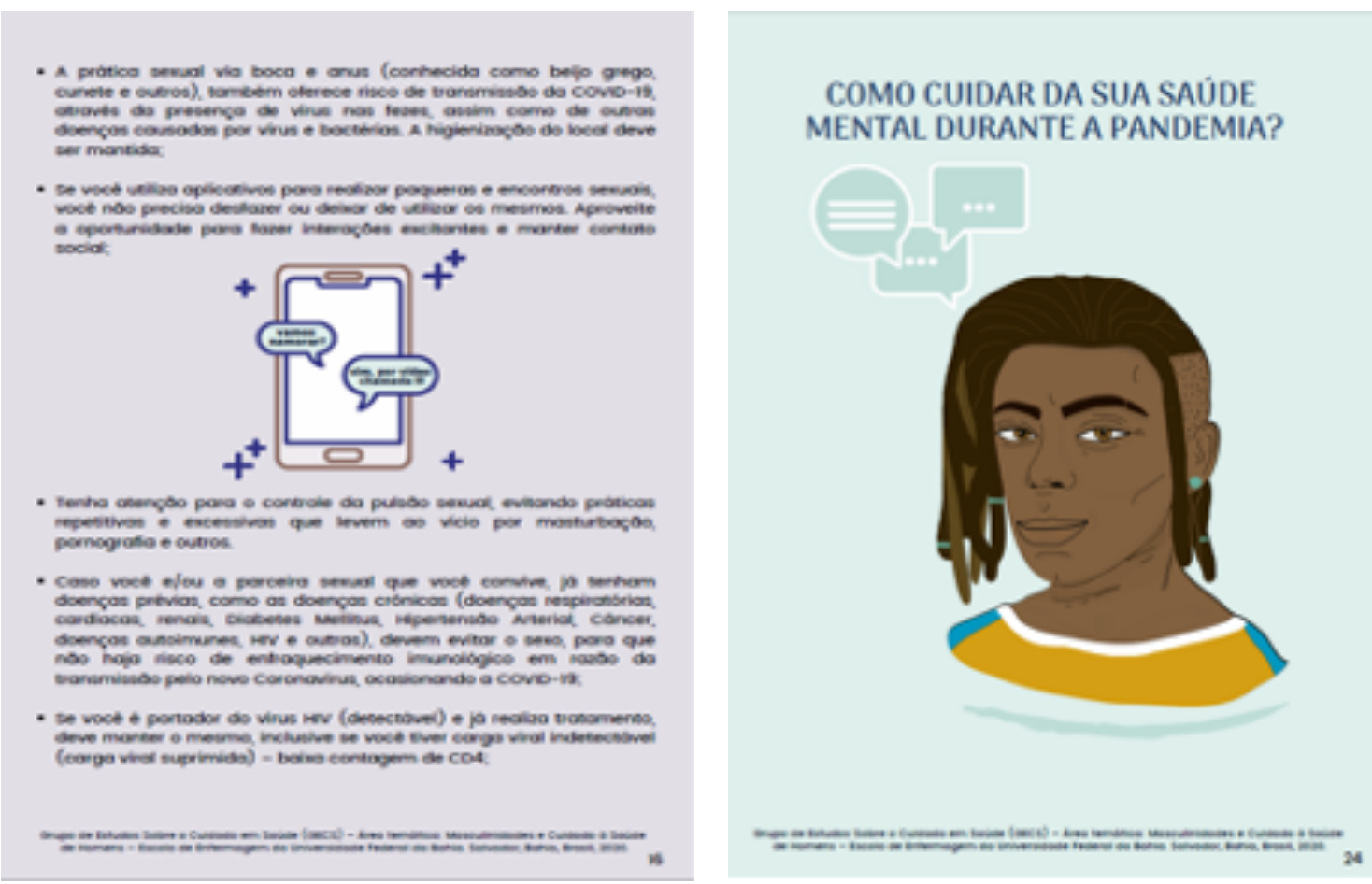

Fonte:

Elaboração

própria,

Salvador, Bahia, 2020 
Em convergência, as informações inseridas na capa buscaram promover uma apresentação coerente, atendendo à um formato institucional, dado que se trata de uma produção acadêmica, e por essa razão, descreveu-se o nome e o brasão (logomarca) da universidade, bem como da escola respon- sável e o grupo de pesquisa do qual se vincula os (as) idealizadores (as) do projeto. O tamanho do título e dos tópicos inseridos, buscou atender a critérios de facilitação da leitura por públicos diversos e com possibilidade de limitações, no entanto não se contemplou a linguagem brasileiras de sinais.

Figura 4 - Capa e contra-capa do guia de orientações e apoio para homens no enfrentamento à pandemia do novo Coronavírus (SARS-CoV2) no Brasil.

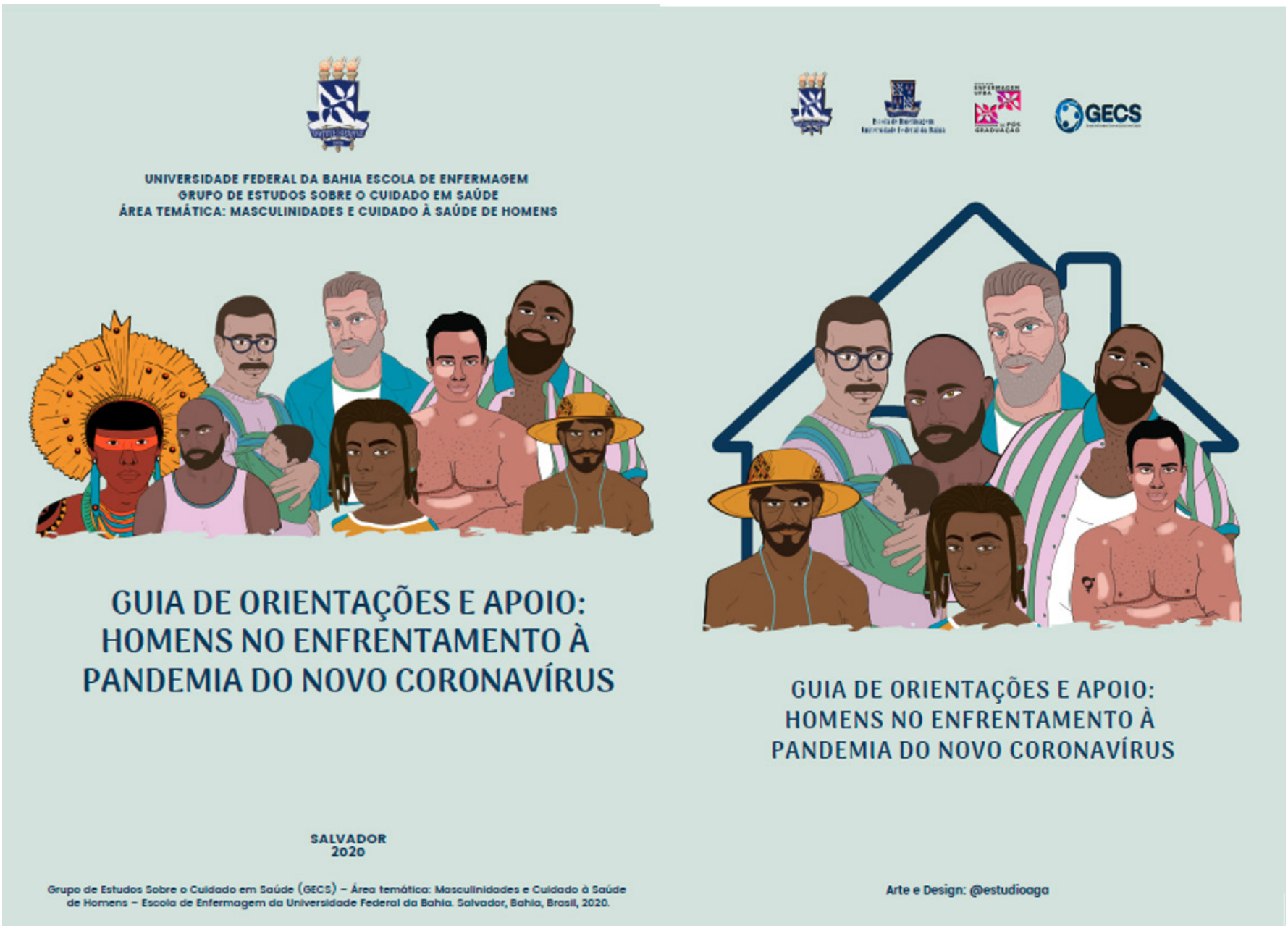

Fonte: Elaboração própria, Salvador, Bahia, 2020

Com base no levantamento das necessidades dos homens, produziu-se uma tecnologia cuidativo-educacional coerentemente adaptada, compativel com as especificidades e singularidades do público masculino, sendo um dispositivo factível, de acesso ampliado e facilitador do aprendizado de homens acerca do desenvolvimento de estratégias de enfrentamento à pandemia do novo Coronavírus (SARS-CoV2) no Brasil.

Limitações da inovação

A inovação limita-se ao seu potencial de alcance no que diz respeito à homens que não sejam alfabetizados, que não tenham acesso aos recursos digitais, assim como aqueles com deficiência visual.

\section{Contribuições para a prática}

Contribuir com a produção do conhecimento científico, nesse momento crucial da pandemia, para melhor compreender a doença e seus efeitos e buscar soluções que amenizem para esses homens sobre a dinâmica da doença e de sua transmissão fornecendo informações sobre a COVID-19.

\section{CONSIDERAÇÕES FINAIS}

Este estudo permitiu descrever resultado de uma inovação tecnológica que se trata da construção de um guia digital para orientações de apoio ao enfrentamento de homens à pandemia no novo Coronavírus (SARS-CoV2) no Brasil. O recurso tecnológico torna-se uma ferramenta 
facilitadora do enfrentamento de homens à pandemia do novo Coronavírus (SARS-CoV2) no Brasil.

Contribuições dos Autores: CCLB: contribuiu com a concepção e/ou desenho, redação do artigo; ARS: contribuiu com a concepção e/ou desenho, análise e interpretação dos dados, redação do artigo, revisão crítica e revisão final; IFM: contribuiu com a revisão crítica e revisão final; CS: contribuiu com a análise e interpretação dos dados, redação do artigo, revisão crítica; ARS: análise e interpretação dos dados, redação do artigo; BHSCL: contribuiu com a análise e interpretação dos dados, redação do artigo; RPR: análise e interpretação dos dados, redação do artigo; AP: contribuiu com a revisão crítica.

\section{REFERÊNCIAS}

1.Guan W, Ni Z, Hu Y, Liang W, Ou C, He J et al. Clinical Characteristics of Coronavirus Disease 2019 in China. The New England Journal of Medicine. This article was published on February 28, 2020, and last updated on March 6, 2020, at NEJM.org. Disponivel em: DOI: 10.1056/NEJMc2005203

2. Johns Hopkins University. Coronavirus COVID-19 Global Cases by Johns Hopkins CSSE [Internet]. Johns Hopkins University; 2020 [acessado em 6 mar. 2020]. Disponivel em: Disponivel em: https://gisanddata.maps.arcgis.com/apps/opsdashboard/index. html\#/bda7594740fd40299423467b48e9ecf6

3.World Health Organization. Coronavírus. Disponivel em: https://www.who.int/emergencies/diseases/ novel-coronavirus-2019/situation-reports/

4.To KKW, Tsang OTY, Leung WS, Tam AR, ChiuWu T, Lung DC. Temporal profiles of viral load in posterior oropharyngel saliva samples and serum antibody responses during infection by SARS-CoV-2: an observational cohort study. Lancet Infect Dis 2020. Disponivel: DOI: https://doi.org/10.1016/S14733099(20)30196-1.

5. Silva, AAM. Sobre a possibilidade de interrupção da epidemia pelo coronavirus (COVID-19) com base nas melhores evidências científicas disponíveis. Rev. bras. epidemiol., Rio de Janeiro. (23): 200021, 2020. Disponivel em: http://dx.doi.org/10.1590/1980549720200021

6. Ziad A. Family Cluster of Middle East Respiratory Syndrome Coronavirus Infections. N Engl JMed 368;26 nejm.org june 27, 2013. Disponivel em: DOI: 10.1056/NEJMoal303729

7. Sousa AR, Queiroz AM, Florencio RMS, Portela PP, Fernandes JD, Pereira A. Homens nos serviços de atenção básica à saúde: repercussões da construção social das masculinidades. Revista Baiana de Enfermagem, Salvador, v. 30, n. 3, p. 1-10, jul./set. 2016. Disponível em: DOI 10.18471/rbe.v30i3.16054
8. Ministério da Saúde (BR). Coronavírus. Disponível em: https://covid.saude.gov.br/.

9. Rosemberg CE. Explaining epidemics and other studies in the history of medicine. Cambridge University Press. 1992

10. Salbego C. Tecnologias cuidativo-educacionais: a práxis de enfermeiros em um hospital universitário [Dissertação] [Internet]. Santa Maria: Universidade Federal de Santa Maria; 2016 [cited 2017 Mar 15]. Available from: http://coral.ufsm.br/ppgenf/ images/Dissertacoes_alunos/Dissertacao_Cleton_ Salbego.pdf

11. Ministério da Saúde (BR). Departamento de Ações Programáticas e Estratégicas. Política Nacional de Atenção Integral à Saúde do Homem: princípios e diretrizes [Internet]. Brasília; 2009. [citado 2015 jun 28]. Disponivel em: http://bvsms.saude.gov. br/bvs/ publicacoes/politica_nacional_atencao_ homem. pdf

12. Vieira LCS, Figueiredo MLF, Sales RLUB, Lopes WMPS, Avelino FVD. A política nacional de saúde do homem: uma reflexão sobre a questão de gênero. Enfermagem em Foco 2011; 2(4):215-217. Disponivel em: http://revista.cofen.gov.br/index.php/enfermagem/article/view/186/122

13. Felix MAS, Maia FOM, Soares RAQ. Atenção primária à saúde e educação em enfermagem no brasil. Disponivel em: Enferm. Foco 2019; 10 (6): 175-181.

14. Machado ME, Paz AA, Linch, GFC. Uso das tecnologias de informação e comunicação em saúde pelos enfermeiros brasileiros. Enferm. Foco 2019; 10 (5): 91-96. Disponivel em: http://revista.cofen.gov. br/index.php/enfermagem/article/view/2543/639

15. Cunha CLF, Ramalho NM. Protocolos de enfermagem: promovendo o acesso e qualidade da assistência na atenção primária à saúde. Disponível em: file:///C:/Users/ASUS/Downloads/3209-15362-1-PB pdf 